\title{
A PRODUÇÃO DO CONHECIMENTO EM SAÚDE MENTAL E O PROCESSO DE TRABALHO NO CENTRO DE ATENÇÃO PSICOSSOCIAL
}

\author{
PRODUCTION OF KNOWLEDGE IN MENTAL HEALTH AND THE WORK PROCESS AT THE \\ PSYCHOSOCIAL CARE CENTER
}

\section{LA PRODUCCIÓN DEL CONOCIMIENTO EN SALUD MENTAL Y EL PROCESO DE TRABAJO EN EL CENTRO DE ATENCIÓN PSICOSOCIAL}

\author{
Ana Lúcia Abrahão ${ }^{1}$ \\ Flávia Fasciotti Macedo Azevedo ${ }^{2}$ \\ Maria Paula Cerqueira Gomes ${ }^{3}$
}

Resumo A premência das mudanças no campo da saúde mental provenientes do redirecionamento do modelo assistencial trouxe à cena o tema da formação como elemento decisivo para a sustentação do processo de reforma psiquiátrica brasileira. Este artigo apresenta resultados da pesquisa "Política de saúde mental no município do Rio de Janeiro: um estudo sobre as metodologias de formação e qualificação das equipes de saúde mental", que teve como objetivo estudar o modo como as equipes dos centros de atenção psicossocial do município do Rio de Janeiro produzem sua agenda de formação permanente em saúde mental e como os profissionais reconhecem as formas de produzir conhecimento, pensar e agir no encontro com o trabalho e a produção do cuidado. Empregamos a observação simples e o grupo focal para coleta de dados. A análise do material procurou identificar a associação das práticas discursivas, que desenham territórios existenciais, com a prática pedagógica no processo de trabalho, articulada ao conceito de analisador. Nesse processo de investigação, foi possível identificar a produção de novas referências de saber, produzidas no ato do trabalho, capazes de transformar o mundo do trabalho e de ativar um cuidado ético, responsável e centrado nos interesses dos usuários.

Palavras-chave saúde mental; educação permanente; pesquisa interdisciplinar.
Abstract The urgency of changes in the field of mental health derived from the redirection of the assistance model introduced the issue of training as a decisive element to support of the Brazilian psychiatric reformation process. This article presents the results of the "Mental health policy in the city of Rio de Janeiro: A study on the methods of training and qualification of mental health teams" research project, which aimed to study how the psychosocial care teams at the psychosocial care centers in the municipality of Rio de Janeiro, Brazil, produce their continuing education agenda in mental health and how the professionals recognize the ways of producing knowledge, thinking, and acting at the place where work and the production of care come together. We use simple observation and focus groups to collect data. The analysis of the material sought to identify the association of the discursive practices, which draw existential territories, with the pedagogical practice in the work process, joined with the analyzer concept. In the investigation process it was possible to identify the production of new knowledge references, produced during work, capable of transforming the labor world and enabling ethical, responsible care, one that is focused on the users' interests.

Keywords mental health; permanent education; interdisciplinary research. 


\section{Introdução}

O processo de transformação no campo da saúde mental remonta a mais de trinta anos de luta com importantes avanços no debate clínico, político e social. A mudança de modelo assistencial ganhou institucionalidade com a lei n. 10.216/2001 e a portaria n. 336/2002, a qual estabeleceu os centros de atenção psicossocial (CAPSs) como unidade de atenção à saúde estratégica para a concretização do processo de reforma psiquiátrica. Os CAPSs são estabelecimentos que visam ao atendimento médico e psicossocial de pessoas em sofrimento psíquico em um processo que estimula a integração social e familiar, com o objetivo de apoiá-los em ações que levem à construção da autonomia dos usuários. Essas unidades fazem parte de uma rede de organizações que buscam substituir o hospital psiquiátrico no Brasil. Desde então, esse dispositivo tem sido foco de grande investimento por parte do governo federal, de modo a garantir a efetivação de mudanças assistenciais, operando transformações no cenário brasileiro desde 1999. Em 2011, contávamos com 1.742 CAPSs distribuídos por todo o país - um volume significativo no processo de reforma psiquiátrica (Brasil, 2012).

A criação de dispositivos assistenciais instituiu uma nova direção de trabalho, com a introdução de elementos na rotina das equipes de saúde mental. Surgiram desafios, descobertas e embates cotidianos na construção de projetos terapêuticos, orientados por novas diretrizes e perspectivas de cuidado (Gomes et al., 2013) - desafios que, no processo de trabalho, não dissociam o cuidado da produção do conhecimento em ato.

Nessa perspectiva, a pesquisa aqui apresentada centrou sua investigação na interface dos campos da saúde e educação, tendo como eixo de sustentação o entendimento do campo do trabalho em saúde como um território de práticas e saberes que se constitui na articulação entre um agir produtivo tecnológico, material e não material, e o mundo das necessidades de saúde, objeto da sua prática (Merhy, 2005). Explorar o trabalho em saúde com base nas possibilidades de aprender e ensinar constituiu o campo de investigação do estudo que deu origem a este artigo.

Ao considerar o CAPS um dispositivo privilegiado na implementação das ações de mudança, a pesquisa se ocupou em investigar como as equipes dos centros de atenção psicossocial do município do Rio de Janeiro vinham produzindo sua agenda de formação permanente em saúde mental. Neste artigo, exploramos a segunda parte da pesquisa "Política de saúde mental no município do Rio de Janeiro: um estudo sobre as metodologias de formação e qualificação das equipes de saúde mental" (Cerqueira Gomes, 2013),4 financiada pela Fundação Carlos Chagas Filho de Amparo à Pesquisa do Estado do Rio de Janeiro (Faperj), tendo como foco as equipes dos CAPSs do município do Rio de Janeiro. O objetivo deste artigo consistiu em mapear o 
conhecimento produzido pelas equipes dos centros de atenção psicossocial desse município.

\section{Trajetória da investigação}

A pesquisa aqui apresentada foi do tipo descritiva, de abordagem qualitativa, em que se utilizaram como instrumentos de coleta dos dados a observação simples e o grupo focal. A observação simples se configurou como uma aproximação inicial do cotidiano de trabalho nas unidades de saúde mental selecionadas, com o objetivo de mapear as formas de institucionalização dos serviços: especificidades da organização do trabalho, tipo de articulação com outras unidades de saúde, equipamentos disponíveis, dinâmica do trabalho com a supervisão, aplicabilidade das discussões de educação permanente e panorama do perfil dos trabalhadores. O grupo focal consistiu em uma técnica de pesquisa qualitativa cujo objetivo é - mediante uma discussão em grupo sobre tópicos específicos fornecidos e 'focalizados' pelo pesquisador - capturar as diferentes representações, percepções e atitudes acerca de um fato, de uma prática ou de um produto final (Minayo, 2006).

Segundo Gatti (2005, p. 9), “há interesse não somente no que as pessoas pensam e expressam, mas também em como elas pensam e por que pensam". 'Como' e 'por que' pensam promovem a busca de novas compreensões e de um novo olhar sobre os processos, capaz de incluir divergências e contraposições.

O processo investigativo tomou como cenário os CAPSs cujas unidades selecionadas cumpriam os seguintes critérios: estarem localizadas em áreas centrais e limítrofes ao perímetro urbano; contemplarem diferentes tipologias de serviços, ${ }^{5}$ como CAPS tipo II e CAPS AD; 6 disporem de supervisão clínico-institucional; terem estabilidade da equipe de saúde, depreendida mediante o tipo e o período de vínculo dos profissionais na unidade.

No final, selecionaram-se oito $(n=8)$ CAPSs que atenderam aos critérios da pesquisa, em diferentes pontos da cidade do Rio de Janeiro. Os participantes do estudo foram profissionais de saúde vinculados aos CAPSs, de diferentes categorias profissionais, seguindo os critérios para a inclusão na pesquisa: ter mais de um ano de trabalho na mesma equipe; participar das reuniões de equipe; possuir vínculo empregatício e aceitar o termo de consentimento livre esclarecido, aprovado pelo Comitê de Ética n. 396/2009. O total de participantes foi de quarenta profissionais $(\mathrm{n}=40)$.

A dinâmica do trabalho de campo consistiu em selecionar uma dupla de pesquisadores e bolsistas, alunos de graduação, que ficaram responsáveis pelo acompanhamento e pelo processo de implantação da pesquisa em cada um dos CAPSs. Foram estabelecidas algumas etapas: contato com o coordenador do serviço para apresentação da pesquisa e dos objetivos do projeto durante 
reunião de equipe do CAPS; observação da reunião de equipe; aplicação do grupo focal na reunião de equipe; e grupo de devolução dos resultados.

Esse processo durou em média de dois a três meses para cada CAPS. A pesquisa foi aplicada simultaneamente em dois ou mais centros de atenção psicossocial. Todos os bolsistas e pesquisadores participaram da pesquisa em dois ou mais serviços, o que contribuiu para a ampliação da capacidade de análise das questões relacionadas pelos grupos, potencializando o posterior processo de discussão dos resultados.

A coleta de dados ocorreu de agosto a novembro de 2011 e foi realizada com o auxílio de um pesquisador moderador, de modo a garantir que os grupos trabalhassem sobre os tópicos de interesse do estudo. Esse pesquisador atuou nos grupos focais da forma menos diretiva possível. A pesquisa contou ainda com um assistente, que observou a conduta dos grupos e dos pesquisadores. Todas as reuniões e o grupo focal foram gravados com o consentimento dos participantes e transcritos integralmente. Com a finalidade de garantir o anonimato das falas dos profissionais, não se identificaram os tipos de serviços na análise dos dados. A garantia do anonimato foi um pedido presente em todas as equipes para a participação nos grupos focais.

Os grupos foram formados pelos profissionais que integravam as equipes dos oito serviços escolhidos, em um total de dez enfermeiros, oito médicos, nove assistentes sociais, 12 psicólogos, 11 técnicos de enfermagem, seis recepcionistas e sete auxiliares de serviços gerais, além de oito supervisores e oito diretores dos CAPSs. Os encontros o grupo foram realizados no dia da supervisão semanal da unidade, quando toda a equipe costuma estar presente. Durante o grupo focal, fechou-se a unidade para atendimento externo.

Com duração média de uma hora e meia, cada grupo foi composto de seis a oito participantes divididos entre as equipes do serviço, de modo a garantir que cada grupo fosse formado por profissionais de diferentes profissões.

\section{Apresentação e análise dos dados}

O material colhido no contato com o campo permitiu captar os movimentos contínuos e descontínuos do trabalho vivo na sua dinâmica, revelando também os afetos e as manifestações desejantes na produção da realidade entre as equipes dos serviços pesquisados.

A análise do material procurou identificar a associação das subjetividades e práticas discursivas que desenham territórios existenciais, relacionados à prática pedagógica e ao conhecimento no trabalho. Nesse processo, adotamos a construção de analisadores como ferramenta analítica. Segundo Lourau (1993), analisador é o que agita a instituição, é o que de uma só vez permite 
surgir uma análise, revelando movimentos antes invisíveis. É um conceito muito útil e bastante interessante para um estudo que objetivava identificar como os profissionais reconheciam as formas de produzir conhe-cimento, pensar e agir no encontro com o trabalho e na produção do cui- dado, além dos fluxos de subjetividades no interior das práticas no trabalho em saúde.

De acordo com L'Abbate (2002):

O efeito de um analisador é sempre o de revelar algo que permanece escondido, de desorganizar o que estava de certa forma, organizado, de dar um sentido diferente a fatos já conhecidos. Isto vale, tanto para as análises de fenômenos sociais mais amplos (os exemplos são inúmeros: a escravidão na Grécia Antiga; o proletariado na sociedade capitalista, o movimento de maio de 68 na sociedade francesa, etc.), como para as análises construídas a partir de processos de intervenção com grupos mais restritos. Em ambos os domínios, descobrir e assinalar quais são os analisadores vai depender da sensibilidade e do treino do socioanalista (L'Abbate, 2002, p. 59).

Dessa forma, o analisador é o que faz aparecer coisas que estão ali, mas não estão visíveis. Como afirma Lourau (1993), um analisador faz uma instituição e seus atores falarem, dizerem coisas que não são conversadas mesmo estando ali, ocultas, mas acontecendo.

O analisador, como opção de análise do material, foi construído nos encontros com os profissionais no serviço - na observação ou durante o grupo focal. Essa construção se deu por meio das numerosas narrativas dos trabalhadores desses serviços sobre como desenvolviam suas atividades no cotidiano. Foi possível montar um quadro referencial que indicava como as equipes produziam seu agir em saúde e como reconheciam ou não os espaços do trabalho como espaços de formação e qualificação.

As narrativas dos diferentes atores do cuidado, durante o grupo focal, deflagraram os modos de construção dos cenários cotidianos do trabalho dando visibilidade à forma como as equipes operavam as relações - e a maneira como o conteúdo subjetivo fluía e era registrado pelo grupo na forma de representações da realidade. No campo da pesquisa em saúde e em educação, as narrativas têm um papel fundamental. Todos os envolvidos assumem uma forma de narrar fatos, acontecimentos e ações; trata-se de uma posição narrativa.

Para Passos e colaboradores (2010, p. 151), a política da narratividade pode ser pensada por meio da posição que assumimos em relação ao mundo e a nós mesmos: "sendo assim, o conhecimento que exprimimos acerca de nós mesmos e do mundo não é apenas um problema teórico, mas um problema político". 
Os registros das narrativas de cada grupo foram além do seu conteúdo. Assim, o timbre, a textura, as ondas de afetos, que iriam se expressar em uma espécie de texto oculto, foram incluídos nesses registros que, muitas vezes, atravessavam as falas e as atitudes assumidas pelas pessoas nos grupos e na sua relação com a atividade sugerida. Um mergulho na micropolítica se produz sempre a partir do agir cotidiano coletivo e de cada um, que nos seus lugares específicos procuram operar o processo de trabalho de acordo com seus projetos singulares, que refletem de alguma forma o modo como significam a produção do cuidado e seus processos formativos (Merhy, 2002).

A análise das narrativas dos profissionais possibilitou identificar conteúdos referentes ao que as equipes entendiam por processos de formação em saúde mental e sua articulação ou desarticulação com o cotidiano de trabalho nos CAPSs, assim como importantes reflexões e sugestões construídas pelos grupos com base nas questões disparadas pelo grupo focal.

Assim, de maneira geral, em que pesem a história e os movimentos singulares de cada serviço, foi possível perceber, mediante a dinâmica provocada pela investigação, dois grandes movimentos nas equipes: um que tomava o cotidiano do trabalho em si, suas tensões e ações como um espaço de formação permanente; e outro que transferia para um espaço externo, como o das instituições de ensino ou das secretarias de saúde, a responsabilidade pela agenda de formação.

Como produto desse processo de análise, que articula a narrativa dos profissionais e os analisadores, foi possível identificar dois grandes movimentos produzidos pelos grupos que diziam respeito a como as equipes dos CAPSs do município do Rio de Janeiro reconheciam as formas de produzir conhecimento, pensar e agir no encontro com o trabalho e na produção do cuidado: 'quando as equipes identificam espaços externos aos serviços como os responsáveis pela agenda de formação'; e 'quando as equipes reconhecem seus cotidianos de trabalho como espaço privilegiado para as suas formações'. Ambos trouxeram fortemente o território do serviço como ordenador da demanda e da produção de conhecimento no cuidado em saúde.

\section{Quando as equipes identificam espaços externos aos serviços como os responsáveis pela agenda de formação}

Um efeito imediato da transferência de responsabilidade pareceu ser uma fixação quase que exclusiva nas tensões do cotidiano do trabalho por parte dessas equipes, em detrimento das discussões sobre a produção do cuidado. De forma geral, as narrativas, sistematizadas mediante a observação e o produto dos grupos focais, enfatizaram a sobrecarga do dia a dia, os conflitos, a precariedade dos recursos físicos, materiais e humanos. 
Percebeu-se a captura desses coletivos por um universo denso, de sofrimento e baixa resolutividade dos casos, dada a escassez de oferta da rede de saúde mental. Houve um conjunto de narrativas que deu ênfase à falta de investimento da gestão em ações de formação no serviço.

As narrativas foram organizadas em destaque identificadas de acordo com a ordem de análise. Assim: narrativa 1, narrativa 2 etc.

(...) o dia a dia do serviço, o enfrentamento das crises sem recursos, sem pessoal, não tem sido fácil. A nossa equipe está imensamente desgastada, nossos profissionais vivem adoecendo, pedindo licença. (...) o dia a dia do trabalho não é mole, não! A secretaria bem que podia oferecer uns cursos de capacitação e atualização para que a equipe pudesse sair um pouco do serviço, dar um descanso na loucura, como dizia a Clarice (Narrativa 5).

(...) Sabe quanto tempo não saio para fazer uma atualização dos temas em saúde mental? (risos) Nunca saí! A secretaria não investe nesses programas de forma regular, e quando oferece há poucas vagas. Será que vai existir o dia em que a qualificação das equipes de saúde mental será uma prioridade para a gestão? Vocês vão falar disso no resultado dessa pesquisa? (Narrativa 3).

(...) fiquei dois anos e meio fora da saúde mental e quando voltei achei que ia tá bombando o meu e-mail de cursos, mas isso meio que deu uma apagada nos últimos anos. Acho que o pessoal está sentindo falta disso também. Essa formação desses cursos, e aí não só os cursos (...) (Narrativa 7).

Foi possível identificar que o cotidiano do trabalho estava imerso em tensões e imprevistos que tomavam todos de surpresa e, ao que parece, sem muita oportunidade para reflexão. As narrativas chamaram a atenção para o cansaço dos profissionais e do não reconhecimento de espaços criativos no interior dos serviços capazes de tomar esses impasses cotidianos como possíveis de produção de conhecimento. Também deixavam clara a expectativa não atendida de formação, com o investimento reduzido em ofertas de cursos que viessem a sanar as dúvidas durante o cuidado.

O não reconhecimento de espaços na formação capazes de lidar com as situações cotidianas dificultava a construção de alternativas para o enfrentamento dessas questões, aumentando o grau de tensão e o sentimento de desgaste no dia a dia dos serviços.

(...) acho que trabalhar em CAPS tem prazo de validade. É tudo muito intenso, as situações são muito graves, e muitas vezes ficamos sozinhos para dar conta de tudo (...) não há um dia que não tenho que lidar com uma situação de crise, já falei mais de uma vez que preciso de um treinamento específico. Há muito tempo que 
não temos esse tema trabalhado. Antes, nos fóruns de saúde mental, a gerência sempre procurava saber quais eram as principais questões de suas equipes; de um tempo para cá não se vê mais isso! (Narrativa 1).

(...) alguns problemas que a gente levantou: poderíamos ter uma melhor utilização da supervisão, das reuniões de equipe, pelo nosso grupo também ser muito grande, o que também dificulta... e que as reuniões externas, pelo menos as que a gente tem podido participar, tem sido mais político-operacional, não muito de produção de saber. Pensamos em espaços de grupo de estudos, mas o nosso município não prioriza, e essa questão também do interesse pessoal de cada um, de participação em cursos, congressos, encontros etc. Algumas vezes aqui nesse serviço houve uma mobilização para grupos de estudos, houve essa tentativa, porém isso se perde, acaba ficando em segundo plano, que abrimos mão para realizar as nossas atividades de assistência. Pensamos também que nós precisamos nos abrir mais, ficamos muito aqui dentro, né? É... a inclusão da diversidade profissional, alguma coisa ligada à experiência no campo, no lado externo. A gente tem pensado esse trabalho do território, a gente tem pensado a partir das nossas ideias, de estar ali no local e construir alguma coisa. Essa foi a nossa discussão (Narrativa 3).

Outro fato destacado nas narrativas dos profissionais das equipes foi a emergência de um sentimento de não reconhecimento e valorização de seus trabalhos por parte dos gestores.

(...) no município ' $\mathrm{X}$ ', toda a rede CAPS passa pelo menos por uma ação de capacitação. A secretaria, ao analisar os indicadores do serviço, propõe os temas dos cursos de atualização para as equipes de saúde mental (...) o profissional é mais bem cuidado nas suas necessidades. Aqui, não há aumento, a contratação agora só por OS [Organização Social], os salários são diferentes, mas o tipo de atendimento é o mesmo, incentivo do estudo só para os que estão chegando com esses introdutórios. Acho que é intencional, é para desestimular os antigos! (Narrativa 8).

Interessante observar na narrativa que os profissionais exploraram a necessidade de apoio no campo da formação para suporte das ações desenhadas no trabalho no CAPS, que se inseriam em diferentes frentes, como seminários, congressos, cursos etc. Por sua vez, a dinâmica que se apresentava no cotidiano era pouco explorada como possibilidade de pensar temas e propor ações de formação. 


\section{Quando as equipes reconhecem seus cotidianos de trabalho como espaço privilegiado para as suas formações}

As equipes, independentemente da categoria profissional, reconheciam em sua prática cotidiana a possibilidade de produzir estratégias inovadoras que ampliassem o cuidado em saúde mental. Esse reconhecimento fazia com que no dia a dia observassem atentamente as formas como produziam conhecimento sobre o cuidado de seus pacientes; como se abriam ou não para reconhecimentos dos distintos planos de cuidado que circulavam no cotidiano dos serviços, ou seja, dos profissionais, dos usuários, dos familiares; como também se abriam para analisar seus múltiplos processos de trabalho; como faziam do mundo do trabalho, na sua micropolítica, um lugar de produção de conhecimento e saber e reconheciam a potência de seus trabalhos e a possibilidade de criar sempre novos agenciamentos para os planos de cuidados de seus pacientes, muitas vezes onde não se conseguia mais apostar.

Os campos dos saberes são abertos, são como horizontes sem fronteiras, o saber popular, o saber científico, o saber profissional, o saber daquele que sofre, o saber do aprendiz, enfim devem se transversalizar e produzir novos encontros, novos saberes. Isto significa dizer que quem sabe de sua dor, de seu sofrimento, é o sujeito que sofre! Significa dizer que linhas ou redes de cuidados produtoras de vida não podem dispensar o sujeito que sofre da construção ativa de seu plano de cuidado! Isso a gente aprende todo dia aqui! É a maior lição que aprendi desde que trabalho nesse serviço (Narrativa 4).

O fato de tomarem seus serviços e encontros que ali eram produzidos como formadores trazia para a cena a possibilidade de se exercer em ato a multiplicidade como um potencializador do cuidado. Vale ressaltar que o reconhecimento das diferenças tinha o estímulo dos supervisores nesse processo, abrindo espaço indubitavelmente para o novo, para o reconhecimento do não saber diante do outro, daquilo que era estranho e, por isso mesmo, tornava-se elemento para a criação, para a invenção de si, do mundo e dos dispositivos.

Assim, o encontro com as múltiplas e infinitas formas de existir da clientela iria demandar infinitos agenciamentos para se produzir um cuidado centrado no sujeito que sofre, incluindo o seu saber sobre o seu adoecimento. Percebeu-se na narrativa dessas equipes uma espécie de fenômeno da multiplicação dos recursos e estratégias de cuidado. Aqui, o exercício da 
tecnologia leve, 7 relacional, era sustentando por meio do agir em saúde dessas equipes (Merhy, 2002).

(...) o momento em que você está com o paciente também é um espaço de formação. Tem alguma coisa que acontece que te apresenta ali uma coisa diferente que você vai estar levando, como espaço de formação mesmo. Tem uma coisa que acontece ali que gera conhecimento, alguma coisa momentânea, que muitas vezes é intuitiva, às vezes é difícil de descrever, mas que é um aprendizado. É um local, é um momento de aprendizado! (Narrativa 2).

Por sua vez, esses agenciamentos só são produzidos em uma rede não linear que não fica capturada em uma história única, em um espaço único. Uma rede preenchida por encontros (Guattari, 1992).

Ao que parece, essas equipes operavam com um conceito de rede viva, que se constrói a cada encontro produzido pelos seus agenciamentos dentro e fora do serviço. Uma produção de rede que não opera pela via do instituído, do que está previamente determinado; ao contrário, as redes vivas são produzidas em acontecimento, em movimento circunstancial, montam e se desmontam. Elas emergem em qualquer ponto do cuidado sem obedecer a uma lógica ou a uma medida protocolar (Merhy et al., 2014).

Identificar os elementos produzidos durante o aprendizado com os profissionais constituía-se em uma das ações do supervisor clínico. Assim, a própria produção da rede, em ato, na prática tornava-se um conceito-ferramenta, capaz de conectar a teoria e a prática. Retornava para a equipe e seus pacientes na forma de sustentação de um determinado cuidado, seu território e suas formas possíveis de andar a vida. Multiplicavam-se as estratégias de intervenção e as possibilidades de manejar uma situação, na medida em que a equipe reconhecia o espaço do serviço, seus encontros, redes de subjetivação produzidas no seu coletivo como um dos infinitos recursos para desenhar os planos de cuidado.

Amplia-se o olhar e as tecnologias para a produção do cuidado em saúde mental. Há um deslizamento de uma produção de cuidado procedimento-centrado para uma produção de cuidado encontro-centrada. O espaço do serviço, o encontro entre as equipes, entre os diferentes saberes em circulação produzem atos pedagógicos porque são capazes de extrair da experiência aprendizado e inovações tecnológicas. Ao mesmo tempo, ao produzir as inovações tecnológicas produzem atos de cuidado porque sustentam práticas inovadoras, criativas, centradas nas necessidades da população que se pretende assistir.

(...) Sabe por que considero que esse serviço é atravessado por espaços de educação permanente? Porque aprendo todo dia. Desde que cheguei aqui, não tem 
um dia igual ao outro, mesmo que muitas das vezes estejamos repletos de situações de crise, de graves enfrentamentos. Só para dar um exemplo, quando B. entra em crise, a crise é dela, e cada vez é diferente. Depende de quem está na frente, do local onde ela está, e se aconteceu aqui ou lá fora. Vocês já viram ela no Nise [Hospital Psiquiátrico Nise da Silveira]? Já viram como é aqui e como é na rua? Por isso que o trabalho no território é fundamental, conhecer como nossos pacientes andam nesses lugares é fundamental para pensar novas estratégias de tratamento. (...) Quando penso sobre isso estou produzindo conhecimento, não? Isso não é uma ação que faz a gente aprender com a prática? Ou produzir conhecimento é só quando a gente escreve a respeito? Acho que não, acho que não! (Narrativa 1).

(...) nossa, quando cheguei aqui achava que sabia de tudo, que lidar com a psicose era para poucos, só para quem estuda muito a respeito (...) nunca vou esquecer da Dona L. com o A [o profissional refere-se a um colega de nível médio que, quando começou a trabalhar no serviço, não tinha experiência no campo da saúde mental] na oficina. Impressionante o que ela fez com ele, eu com toda a minha experiência anterior jamais ia pensar naquela intervenção, às vezes a gente fica cheio de teoria, protocolo e esquece de olhar o que está acontecendo ali. Agora, sempre que posso, procuro saber como cada um da equipe lida com meus pacientes. (...) Muitas vezes, na reunião de supervisão, me surpreendo com um relato sobre meus pacientes, ou mesmo uma forma de agir que eu não conhecia. Isso é fantástico, não dá nos livros! (risos) (Narrativa 7).

Percebeu-se que esses encontros eram substituídos a cada vez que a equipe estava diante de um caso em relação ao qual a rede já constituída encontrava dificuldades de oferecer outras formas de cuidar. Para que essa irreversibilidade se sustente, é preciso reconhecer que há na cidade, nos territórios, nas vizinhanças, espaços ainda não navegados que nunca vão se esgotar, porque eles são constituídos com base em histórias singulares. A consequência imediata dessa posição foi a intensificação do trabalho das equi-pes em articulação com os diferentes territórios na rede de saúde e fora dela.

Ao tomar os múltiplos e distintos processos e espaços de trabalho em análise, produziu-se uma ação crítico-reflexiva que movimentava essa rede, em que a supervisão clínica ou institucional poderia ser um apoio a esse movimento. Faz com que essa rede se produza como uma fabricação constante. Afirmando distintas realidades que não param de produzir a si mesma. Portanto estão em processo ininterrupto de modificação e reinvenção. Posição fundamental quando se quer desconstruir um processo social complexo como a racionalidade manicomial (Guattari, 1992).

Entende-se desconstrução como um processo social complexo, de desmontagem do dispositivo psiquiátrico, que não tem fim, ou não pretende constituir um modelo ideal, mas sim dar novo significado às relações e apresentar 
questões imanentes às situações-problema. Nesse sentido, é um processo que precisa, por definição, ser reinventado incessantemente (Guattari, 1992).

Percebeu-se que as equipes exploravam a potência inscrita nos fazeres produtivos como atos pedagógicos (Franco e Merhy, 2007). Daí o reconhecimento do espaço cotidiano dos serviços de atenção psicossocial como lugar de se debruçar sobre objetos de ações, de fazeres, saberes e agenciamentos dos diversos sujeitos implicados nesses cotidianos.

Entendeu-se que qualquer agenda de formação permanente não pode prescindir da participação dessas equipes na construção dos desenhos de formação. Multiplicavam-se os espaços compartilhados de produção de conhe-cimento e de cuidados em saúde no café, na hora do almoço, na oficina, na convivência, enfim, em todos os lugares onde esses trabalhadores operavam. Desenhava-se, nesses serviços, um coletivo de sujeitos autônomos e críticos, capazes de se reconhecerem como produtores de saber sobre si, seus pares e sobre a clientela de que eram chamados a cuidar.

Eu acho que os CAPS, esse dispositivo, são um espaço privilegiado de formação, porque tem coisas que num consultório particular a gente raramente faz, no ambulatório também não faz, e de fato a gente está sempre podendo ouvir o colega, que atendeu um caso e ficou mal diante de uma situação, ou que ficou bem diante de uma situação. Então, oportunidades que eu acho muito importantes, muito ricas da gente trocar ideia e partir pra outras coisas, pra outras ideias a respeito dos casos, e eu acho que o dispositivo CAPS dá essa condição pra gente. Pra esse trabalho onde vários olhares, vários profissionais, várias especialidades estão ali, sem nenhum estar achando que é mais importante que o outro, mas está todo mundo trabalhando em prol do melhor atendimento ao paciente (Narrativa 2).

Nós, que viemos do hospital psiquiátrico, que é muito fechado, no qual a participação dos profissionais era muito restrita ao saber específico de cada um... Então nós que somos técnicos, nós não tínhamos acesso, é aquilo que ela falou, existia uma divisão de poder, que era aqueles que tinham o saber, e nós que executávamos as ordens. A partir dessa mudança da reforma, houve toda uma mudança de reflexão em cima do trabalho, e a partir disso o CAPS vem e dá coletividade ao trabalho, ele permite que todos nós estejamos aqui, cada um dentro da sua expressividade, mas essa capacidade de, esse modelo de reforma na qual eu posso procurar o que é melhor pra mim, aonde eu me encaixo nesse sistema, qual a importância, a valorização, que em um sistema fechado você não tem. Não tem essa possibilidade de se sentir valorizado. Eu saí da clínica pra vir pra saúde mental, fiz essa escolha, e eu fiz baseado por conta das pessoas que estão aqui, que me conhecem há muito tempo. E esse modelo da reforma fechada era muito doentio, você não tinha a possibilidade... E quando veio a reforma psiquiátrica, nós tivemos a oportunidade de lidar com pessoas que detinham o poder, e que permitiu 
que essas pessoas que estavam lá, que estavam trabalhando, que tinham tanto, como a S., que jamais teria a oportunidade de fazer o trabalho que faz no sistema fechado. Então o CAPS, no meu modo de pensar, é a reforma psiquiátrica como instituição (Narrativa 5).

Foi possível observar que os trabalhadores dessas equipes assumiam a função de protagonistas na produção do cuidado e, ao mesmo tempo, construíam conhecimento por meio da realidade na qual pretendiam intervir, lançando-se a si mesmos como sujeitos. Assim, houve a construção indissociável entre as linhas de cuidado e de produção pedagógica - uma articulação de cenários e processos que ocorriam simultaneamente no cotidiano, na realidade dos serviços investigados.

\section{Considerações finais}

O mergulho no dia a dia dessas equipes, com a possibilidade de recolher o que elas tinham a dizer sobre seu fazer, nos ofereceu novas novos elementos de compreensão sobre o complexo processo de transversalidades e atravessamentos que ocorrem no interior dos serviços de saúde mental. Permitiu trazer para o debate distintas conformações dos modos de educar/formar e trabalhar/cuidar em saúde mental. Os resultados da pesquisa foram ao encontro de trabalhos que reafirmam a urgência de se pautarem na agenda pública novas maneiras de produzir conhecimento e pensar sobre a educação e o trabalho em saúde mental, reconhecendo novos atores, novos papéis, novas referências.

O estudo apresentado neste artigo confirmou o entendimento de que a política de formação só é potente e produtora de mudanças nas práticas de saúde mental se for capaz de criar e sustentar a troca - nos serviços e entre os distintos coletivos que operam na rede de atenção psicossocial - com base na realidade local, com valorização dos diversos saberes e metodologia participativa, construídos por meio do intercâmbio entre municípios, coordenação estadual e instituições formadoras voltadas para profissionais de saúde, em todos os níveis de atenção.

Espera-se que os resultados apresentados tenham se aproximado do atual estado da arte dos movimentos de produção de conhecimento nos CAPSs no município do Rio de Janeiro. Analisá-los e pautá-los na agenda pública para o debate e a produção acadêmica é a aposta que se faz com os resultados desta pesquisa, em direção ao fortalecimento do compromisso dos profissionais e equipes de saúde com um cuidado ético e responsável. Espera-se que o cumprimento dos princípios da reforma psiquiátrica e a qualidade no atendimento do Sistema Único de Saúde (SUS) sejam beneficiários dessa 
transformação, com reflexos no cuidado e na promoção da saúde da população do estado do Rio de Janeiro.

Ao identificarmos esses dois grandes movimentos nas equipes dos serviços - um que toma o cotidiano do trabalho em si, suas tensões e ações como um espaço de formação permanente; e outro que transfere para um espaço externo, como o das instituições de ensino ou das secretarias, a responsabilidade pela agenda de formação -, eles produzem efeitos distintos na produção do cuidado e na formação dos coletivos. É preciso deixar claro que eles também podem ser encontrados em outros serviços, pois são formas múltiplas de operar e entender a formação em saúde mental entre os membros de uma mesma equipe.

Foi possível perceber que quanto mais um determinado coletivo em questão tomava como direção de trabalho a afirmação do serviço como espaço de formação e produção de conhecimento, maior a porosidade encontrada nos processos de trabalho entre os membros da equipe; maior e mais intensa as zonas e os espaços de compartilhamento da produção do cuidado; maior a troca de experiências e, consequentemente, o aumento de tomada de responsabilidade coletiva na construção e sustentação do cuidado. Essa constatação implicou reconhecer como maior a possibilidade de se encontrarem espaços de conexão e intercessão entre os profissionais de uma mesma equipe. Logo, era visível e audível nas narrativas a existência de diferentes espaços de fala e escuta qualificada a sustentar a construção de vínculos afetivos e potentes para lidar com as vicissitudes do cuidado em saúde mental.

\section{Colaboradoras}

Ana Lúcia Abrahão trabalhou na concepção, delineamento, análise e interpretação dos dados, e redação final do artigo. Maria Paula Cerqueira Gomes contribuiu no delineamento, análise e interpretação do dados, redação final do artigo, revisão crítica e aprovação da versão a ser publicada. Flávia Fasciotti Macedo Azevedo cooperou no delineamento, redação final do artigo, revisão crítica e aprovação da versão a ser publicada. 
Resumen La premura de los cambios en el campo de la salud mental provenientes del redireccionamiento del modelo asistencial puso sobre el tapete el tema de la formación como elemento decisivo para la sustentación del proceso de reforma psiquiátrica brasileña. Este artículo presenta resultados de la investigación “Política de salud mental en el municipio de Río de Janeiro: un estudio sobre las metodologías de formación y calificación de los equipos de salud mental", que tuvo por objetivo estudiar el modo como los equipos de los centros de atención psicosocial del municipio de Río de Janeiro, Brasil, producen su agenda de formación permanente en salud mental y cómo los profesionales reconocen las formas de producir conocimiento, pensar y actuar en el encuentro con el trabajo y la producción del cuidado. Empleamos la observación simple y el grupo focal para recolectar los datos. El análisis del material buscó identificar la asociación de las prácticas discursivas, que diseñan territorios existenciales, con la práctica pedagógica en el proceso de trabajo, articulada con el concepto de analizador. En este proceso de investigación, fue posible identificar la producción de nuevas referencias de saber, producidas en el acto del trabajo, capaces de transformar el mundo del trabajo y activar un cuidado ético, responsable y centrado en los intereses de los usuarios.

Palabras clave salud mental; educación permanente; investigación interdisciplinaria.

\section{Notas}

1 Universidade Federal Fluminense, Centro de Ciências Médicas, Escola de Enfermagem, Niterói, Rio de Janeiro, Brasil.

<abrahaoana@gmail.com>

Correspondência: Universidade Federal Fluminense, Centro de Ciências Médicas, Escola de Enfermagem, Rua Doutor Celestino, 74, Centro, CEP 24020-091, Niterói, Rio de Janeiro, Brasil.

2 Secretaria Municipal de Saúde, Rio de Janeiro, RJ, Brasil.

$<$ flaviafmazevedo@gmail.com>

3 Universidade Federal do Rio de Janeiro, Instituto de Psiquiatria, Programa de Psiquiatria, Rio de Janeiro, RJ, Brasil.

$<$ paulacerqueira@gmail.com>

${ }^{4}$ Este projeto foi desenvolvido pela Universidade Federal do Rio de Janeiro (UFRJ), Centro de Ciências da Saúde, Instituto de Psiquiatria pelo Laboratório de Educação, Trabalho e Assistência em Saúde (Letras), por meio do Programa de Pós-Graduação em Clínica Médica, e realizado em parceria com a linha de pesquisa Micropolítica do Trabalho e do Cuidado em Saúde, do Programa de Pós-Graduação em Clínica Médica da Faculdade de Medicina da Universidade Federal do Rio de Janeiro.

$5 \mathrm{Na}$ época da pesquisa, o município do Rio de Janeiro não contava com nenhum serviço de atenção psicossocial do tipo III. Tais serviços só iniciaram suas atividades no segundo semestre de 2013, quando a pesquisa já estava em pleno desenvolvimento dos grupos focais nas unidades.

6 O CAPS tipo II atende pessoas com transtornos mentais graves e persistentes, podendo também atender pessoas com necessidades decorrentes do uso de crack, álcool e outras drogas, 
conforme a organização da rede de saúde local; é indicado para municípios com população acima de 70 mil habitantes. O CAPS AD atende adultos ou crianças e adolescentes, considerando as normativas do Estatuto da Criança e do Adolescente, com necessidades decorrentes do uso de crack, álcool e outras drogas; é um serviço de saúde mental aberto e de caráter comunitário, indicado para municípios ou regiões com população acima de 70 mil habitantes.

7 Tecnologia leve, conceito de Merhy (2002) que faz relação com as diversas formas e empregos do saber no processo de trabalho em saúde. Nesse caso, o emprego de tecnologias relativas à escuta, ao aspecto relacional entre profissional e usuário.

\section{Referências}

BRASIL. Ministério da Saúde. Saúde mental em dados 10, ano VII, n. 10. Informativo eletrônico. Brasília, DF, mar., 2012. Disponível em: $<$ https://saudeecosol.files.wordpress.com/ 2012/03/saude-mental-em-dados-10-ms.pdf>. Acesso em: 23 out. 2013.

BRASIL. Lei n. 10.216, de 6 de abril de 2001. Dispõe sobre a proteção e os direitos das pessoas portadoras de transtornos mentais e redireciona o modelo assistencial em saúde mental. Diário Oficial da União, Brasília, 9 abr. 2001. Disponível em: <www.planalto.gov.br/ ccivil_03/leis/LEIS_2001/L10216.htm >. Acesso em: 20 out. 2016.

BRASIL. Portaria GM/MS n. 336, de 19 de fevereiro de 2002. Dispõem sobre os Centros de Atenção Psicossocial. Diário Oficial da União, Brasília, 19 fev. 2002. Disponível em: <http://bvsms.saude.gov.br/bvs/saudelegis/ gm/2002/prt0336_19_02_2002.html >. Acesso em: 20 out. 2016.

CERQUEIRA GOMES, Maria P.; ABRAHÃO, Ana L. Política de Saúde Mental no Estado do Rio de Janeiro: um estudo sobre as metodologias de formação e qualificação das equipes de saúde mental. Relatório final. Rio de Janeiro: Faperj, 2013. Mimeografado.

FRANCO, Túlio B.; MERHY, Emerson E. Produção do cuidado e produção pedagógica: integração de cenários do sistema de saúde no Brasil. Interface: Comunicação, Saúde, Educação, Botucatu, v. 11, n. 23, p. 427-438, set.-dez. 2007.

GATTI, Bernadete A. Grupo focal na pesquisa em ciências sociais e humanas. Brasília: Líber Livro, 2005.

GOMES, Maria P. C. et al. Formação e qualificação: um estudo sobre a dinâmica educativa nas equipes de saúde mental do Rio de Janeiro. Interface: Comunicação, Saúde, Educação, Botucatu, v. 17, n. 47, p. 835-845, 2013.

GUATTARI, Félix. Caosmose: um novo paradigma estético. São Paulo: Editora 34, 1992.

L'ABBATE, Solange. L'argent, un analyseur de l'institution médico-sociale au Brésil. Les Cahiers de L'implication. Revue d'Analyse Institutionnelle, Paris, v. 5, p. 57-69, 2002.

LOURAU, René. Análise institucional e práticas de pesquisa. Rio de Janeiro: EdUerj, 1993.

MERHY, Emerson E. Saúde: a cartografia do trabalho vivo. São Paulo: Hucitec, 2002.

MERHY, Emerson E. Engravidando palavras: o caso da integralidade. In: PINHEIRO, Roseni; MATTOS, Ruben A. (orgs.). Construção social da demanda. Rio de Janeiro: IMS/Uerj, 
Cepesc, Abrasco, 2005. p. 195-206.

MERHY, Emerson E. et al. Redes vivas: multiplicidades girando as existências, sinais da rua - implicações para a produção do cuidado e a produção do conhecimento em saúde. Divulgação em Saúde para Debate, Rio de Janeiro, n. 5, p. 153-164, out. 2014.

MINAYO, Maria C. S. O desafio do conhecimento: pesquisa qualitativa em saúde. 8. ed.
São Paulo: Hucitec, 2006.

PASSOS, Eduardo et al. (orgs.). Pistas do método da cartografia: pesquisa-intervenção e produção de subjetividade. Porto Alegre: Sulina, 2010.

Recebido em 07/02/2015

Aprovado em 11/11/2015 